\title{
Esportes de raquete, motivação, divulgação e infraestrutura: influências sobre a prática
}

\author{
Racket sports, motivation, spreading and infrastructure: influences on practice
}

DOI: http://dx.doi.org/10.36453/2318-5104.2019.v17.n2.p177

\author{
Mateus Augusto de Oliveira Machado, Rodney Rodrigo de Souza, \\ Siomara Aparecida da Silva \\ Universidade Federal de Ouro Preto (UFOP)
}

\begin{abstract}
RESUMO
Introdução: A prática dos esportes em Ouro Preto (MG) está centrada no "quarteto fantástico" que se caracterizam pelos esportes coletivos mais praticados deixando uma lacuna nas experiências motoras advindas de outras modalidades. Objetivo: Descrever as características relacionadas aos esportes de raquete e assim identificar as características que motivam sua prática esportiva após a fase escolar. Métodos: Este estudo apresenta-se sobre o caráter qualitativo descritivo. Utilizando de um corte ex-post-facto. Entrevistas utilizando um roteiro desenvolvido para este trabalho foram feitas em uma escola estadual e em um clube da cidade, com áudio captado. Resultados: Das respostas dos entrevistados emergiram as categorias de análise: “Quase nada, pela televisão com jogos olímpicos a gente consegue ver os esportes com raquete". "Ping-pong, tênis, tem aquele com a peteca (badminton)". Categoria (1) conhecimento. Conclusão: Foi visto com esta pesquisa que a prática dos esportes de raquete sofre influência de vários fatores como a falta de conhecimento das modalidades, motivação, divulgação das modalidades, entre outras, porém apesar disto foi visto que a cidade oferece suporte para o trabalho de algumas das modalidades de raquete e que existe uma população que apresenta interesse de praticar essas modalidades.
\end{abstract}

PALAVRAS-CHAVE: Motivação; Esportes de raquete; Prática.

\section{ABSTRACT}

Background: The practice of sports in Ouro Preto (MG) is centered in the "fantastic quartet" that are characterized by the most practiced collective sports leaving a gap in the motor experiences coming from other modalities. Objective: To describe the characteristics related to racket sports and thus identify the characteristics that motivate their sports practice after the school stage. Methods: This study presents the qualitative descriptive character. Using an ex-post-facto cut. In a state school and a city club interviews were made using a script developed for this work, with audio captured. Results: From the interviewees' answers came the categories of analysis: "Almost nothing, by television with Olympic games we can see sports with racket." "Ping-pong, tennis, there's the one with the shuttlecock (badminton). "Category (1) knowledge. Conclusion: It was seen with this research that the practice of racket sports is influenced by several factors such as lack of knowledge of the modalities, motivation, dissemination of modalities, among others, however despite this it was seen that the city supports the work of some of the and that there is a population that shows an interest in practicing these modalities.

KEYWORDS: Motivation; Racquet sports; Practice. 


\section{INTRODUÇÃO}

O meio esportivo é bastante diversificado na oferta de modalidades. A escolha das práticas pode ser através das características que classificam as modalidades, como coletivas ou individuais (ou em dupla), em utilização de espaços separados ou comuns que favorecem os participantes terem ou não contato entre si, e ainda interferir na intensidade da ação com participação alternada ou simultânea (MORENO, 1994).

Apesar de serem numerosas as modalidades esportivas que a sociedade pode optar em praticar, vivemos em um cenário envolto no que Betti $(1998,2003)$ chama de monocultura esportiva, e também o que Daólio (2007) e Darido (2016) caracterizam como "quarteto fantástico". Ambos os termos se referem ao eixo de prática dos esportes coletivos: Futebol/Futsal, Vôlei, Handebol e Basquete que muitas vezes são sustentadas no primeiro contato do sujeito com a prática esportiva que é na Educação Física escolar. Contudo, sabemos que essas não são as únicas modalidades que podem ser apresentadas para o desenvolvimento das habilidades e de sua continuidade de prática que a população vem buscando a cada dia para se exercitar.

Segundo Tinôco (2014), esportes como o futebol\futsal, vôlei, basquete e handebol são prioritários nas aulas de Educação Física em detrimento a outras manifestações corporais que devem ser utilizadas como temas, tais como: dança, lutas, conhecimento sobre o corpo, jogos e brincadeiras, atividades rítmicas expressivas e ginástica, além de outros esportes não hegemônicos. Esta situação ocorre devido a motivos diversos, sociais ou culturais que não serão nesta pesquisa. Já Betti (1992) aponta que o aluno deverá ser instrumentalizado para usufruir dos jogos, esportes, danças, lutas e ginásticas, conteúdos da educação física escolar, em benefício do exercício crítico da cidadania e da melhoria da qualidade de vida.

Tinôco (2014) ainda afirma que a educação física na escola deveria propiciar condições para que os alunos obtivessem autonomia em relação à prática da atividade física, ou seja, após o período regular de aulas os alunos deveriam manter uma prática de atividade regular, sem o auxílio de especialistas, se assim desejarem. Este objetivo é enormemente facilitado se os alunos encontram prazer nas aulas de Educação Física, pois, apreciando determinada atividade é mais provável o desejo de continuidade de prática.

O sujeito com a escolarização básica deveria ser capaz de reconhecer a diversidade de práticas esportivas e já ter as vivenciado para poder sustentar sua escolha de continuidade na vida adulta. Assim, ele teria autonomia para escolher dentre as práticas esportivas que em seu ambiente fossem facilitadas ou mesmo buscar adequação dessa facilidade em clubes, academias ou centros esportivos. Essa população que emerge do ensino médio para o mercado de trabalho e/ou universidades e que anseiam por padrões de saúde e qualidade de vida e também almejam diversidade de práticas para melhor se encontrarem no cenário esportivo, nesse estudo será considerada como "população emergente" .

Segundo o modelo de desenvolvimento de Gallahue (1992), a fase de 15 aos 18 anos (faixa etária da população emergente) é o período que ocorre o ápice do processo de desenvolvimento e está caracterizado pelo desejo individual em participar de uma atividade que possui número limitado de movimentos. O tempo, condições sociais, dinheiro, equipamento e oportunidades de oferta de práticas são fatores que afetam este estágio de desenvolvimento traçado por contundentes decisões. Dentre essas conciliarem tempo para a prática e afazeres de estudos/trabalho e vida social. Nessa etapa, como fruto do processo anterior, os jovens se deparam com fatores que determinarão se o indivíduo participará de uma prática esportiva para competir, recreação e/ou lazer, ou se ainda assim necessitará dela para manter (ou adquirir) saúde (GRECO; SILVA; SANTOS, 2009).

Frequentar clubes sociais esportivos tende a interferir de forma significativa nos hábitos de vida das pessoas, principalmente, nos hábitos direcionados à prática de atividades físicas. As práticas oportunizadas nos clubes são sustentadas pelos anseios de seus frequentadores, o que segundo Carvalho (1997) promovem práticas voltadas para a arte, esporte, bem-estar físico e atividades sociais de forma individual ou em conjunto.

Estes locais de práticas de atividades físicas são espaços de atuação direta dos bacharéis em Educação Física. Segundo Carvalho (2009) a ideia de que o associado não encontra dentro destes locais, atividades que sejam adequadas, é um ponto de grande importância e que exige reflexão, pois se reflete diretamente nas funções do professor de educação física dentro dos clubes. Carvalho (2009) ainda afirma que mesmo o clube sendo o local tradicionalmente reservado para a prática de esporte no Brasil, a bibliografia sobre o tema é escassa. Vários estudos abrangem o fenômeno Esporte em todas as suas vertentes e apresentam os clubes como um possível cenário em que se acontece à prática esportiva, sem, entretanto, abordar questões relacionadas ao clube, na tentativa de compreendê-la como um espaço de educação informal.

Assim, tendo a diversidade esportiva oferecida à população emergente, sendo ela capaz de decidir sobre qual prática dará continuidade na vida adulta e tendo a oferta dessas nas instituições de cunho esportivo, questiona-se sobre a prática dos esportes de raquete. Quais as características dessa tríade pessoa (população emergente) - ambiente (clubes/ instituições) - e tarefa (responsabilidade de oferta pelo professor). Nitsch (1985), para a prática dos esportes de raquete: 
Será que a população emergente conhece os esportes de raquete além do "quarteto fantástico"? Será que vivenciaram a prática ou tem informações sobre os esportes de raquete? Fator como a falta de conhecimento das modalidades dos esportes de raquete, influenciam na decisão sobre a prática esportiva da população emergente? A motivação dos praticantes e o conhecimento teórico do professor estão relacionados também com a prática dos esportes de raquete?

O eixo norteador de desenvolvimento de esportes com raquete está no desenvolvimento da habilidade motora básica REBATER. A partir desse princípio, sabe-se então que o indivíduo utilizará um instrumento (que deve ser tratado como uma extensão de seu braço) e que, por sua vez, rebaterá um outro objeto, na maioria das vezes uma bola, mas pode ser uma peteca como é o caso do badminton (CHIMINAZZO, 2008, p. 3).

Dessas as mais recorrentes na cultura brasileira são o tênis tradicional, o tênis de mesa, o badminton, o squash e o frescobol, sendo o frescobol uma manifestação do esporte com o intuito de aprendizado nas escolas, mais vale ressaltar que não são apenas esse a forma de se praticar os esportes e sim as mais conhecidas. Dito isso, o objetivo desse estudo é descrever as características relacionadas à prática dos esportes de raquete na cidade de Ouro Preto - MG. Almejando identificar as características que conduzem à prática esportiva para população emergente e se estas influenciam na escolha dos esportes de raquete para a prática.

\section{MÉTODOS}

Este estudo apresenta-se sobre o caráter qualitativo, descritivo. Utilizando de um corte ex-post-facto, com análise do discurso por categorias (THOMAS et al., 2007). A estruturação das questões para a entrevista específica deste estudo foi feita e aplicada em grupos focais de associados de clube e associação atlética (na faixa etária da população emergente e estudantes de escolas estaduais), e alunos de ensino médio, considerados como grupo emergente. As entrevistas duraram em média 5 minutos e foram gravadas e, posteriormente transcritas na integra e entregues aos entrevistados para validação. Antes da realização das entrevistas os procedimentos éticos foram aprovados pelo Comitê de Ética da universidade do coordenador da pesquisa com o número (CAAE $n^{\circ}$. 69917917.7.0000.5150).

Os nomes dos colaboradores foram omitidos, por resguardos éticos, sendo as falas definidas por números dados a cada definição de grupo. Do grupo de professores tivemos a participação de três profissionais: (1) professor de educação física da rede federal de ensino, natural de Ouro Preto com 37 anos de formado; (2) profissional qualificado para dar aulas de tênis certificado pela Confederação Brasileira de Tênis desde 2001; (3) professora de educação física do ensino médio da rede estadual no município há dois anos e meio e 16 anos de formação. Os clubes citados no trabalho tiveram seus nomes alterados para cor amarelo e azul, e as escolas para estadual e federal, para seus resguardos éticos. Assim preserva-se a identificação dos clubes no resguardo ético e continua-se com a possibilidade de continuidade de estudos na cidade.

O grupo emergente, alunos do terceiro ano são aqueles indivíduos que saem para o mercado de trabalho ou universidade com autonomia para escolher uma prática esportiva, foram convidados a participarem voluntariamente da entrevista coletiva. Sendo uma amostra de 8 alunos no clube, 29 alunos na escola estadual e 30 alunos na escola federal. O critério de seleção desse grupo foi aceitaram o convite, estarem nas definições dos grupos quanto à faixa etária, e quanto o clube foi ser um clube localizado na cidade de Ouro Preto (MG), adequado para a prática de pelo menos uma modalidade de esporte de raquete. O critério de exclusão foi o aluno não aceitar ou não ser autorizado pelo responsável a participar do estudo e do clube foi não estar localizado dentro da cidade de Ouro Preto (MG) e sim em seu distrito.

A fidedignidade e a validade das entrevistas se deram com o envio da entrevista digitada na integra, aos entrevistados, e com as respectivas assinaturas respaldando o conteúdo. Para organizar a visualização das categorias que emergiram das falas/conteúdo utilizamos o software Microsoft Excel 2016.

\section{RESULTADOS}

As quatro categorias que emergiram das entrevistas retratam (A) o conhecimento sobre as modalidades (conhecimento declarativo), (B) a vivência prática nas modalidades de raquete (conhecimento processual), (C) o interesse/ motivação em praticar as modalidades no cenário atual, (D) Viabilidade e divulgação da prática das modalidades, vale ressaltar que as categorias relacionam entre si a todo o momento.

Ao se tratar do conhecimento (ou reconhecimento) das modalidades, categoria de (A), que compõem o conjunto de modalidades dos esportes de raquete, os alunos dos grupos emergentes tiveram que raciocinar para responder como se estivessem sendo questionados se sabia ou não jogar as modalidades: 


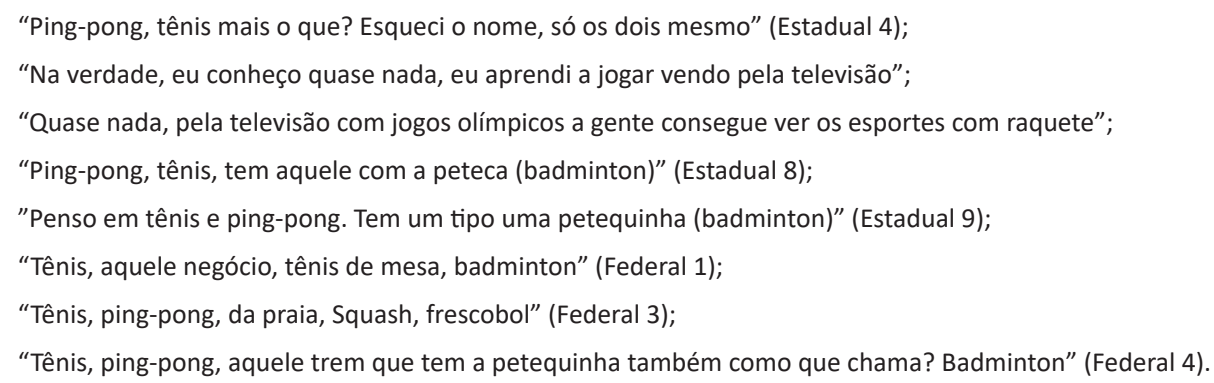

Foi possível visualizar que alunos da instituição federal apresentam um conhecimento dos esportes de raquete diferenciado na variedade de modalidades quando comparado com os grupos da instituição estadual. Entretanto, para os professores licenciados em Educação Física esse tipo de conhecimento já está inserido nos conteúdos da profissão, mas não foram reconhecidos pelos respectivos alunos das duas instituições. Quanto ao entrevistado licenciado pela $\mathrm{CBT}$, o mesmo apresenta um conhecimento processual específico da modalidade a qual trabalha o que infere apenas na reprodução do conhecimento prático adquirido.

Na categoria (C), o interesse/motivação em praticar as modalidades no cenário atual, busca questionar aos entrevistados quanto a sua visão do atual cenário dos esportes de raquete em Ouro Preto, o que se relaciona com o conhecimento da categoria (B): "Olha infelizmente em Ouro Preto o que diz respeito a clube né! o único que a gente tem é o clube "Azul" né, que vem
daquela questão da década de 60 e 70 , que foi onde o governo do estado veio a implantar as praças de esportes, e
clube Azul, hoje e um remanescente disso ai dessa implantação dessas praças de esporte. Mas a não ser aqui o clube
"Amarelo" que também trabalhava praticamente o tênis são as duas possibilidades que a gente tem. Entendeu. Eu
não vejo assim outras iniciativas para o esporte na cidade" (Entrevistado 1);

"Está começando a evoluir, agora teve um projeto da prefeitura um tempo atrás e está surgindo novos professores e o clube Amarelo está fazendo um trabalho bom na base e o clube Azul também está" (Entrevistado 2).

A carência de espaços físicos e de conhecimento sobre os esportes de raquete diminui o aproveitamento de locais disponíveis na cidade para aumentar a oferta de prática. O aumento da disponibilidade de prática na cidade tende a ter mais alunos que apresentem conhecimento das habilidades desses esportes o que levaria a solicitação das práticas nas aulas de educação física. Para Ramos et al. (2008), o domínio do conteúdo pedagógico se relaciona diretamente com o conhecimento teórico e prático especializado, ou seja, o professor que durante a sua graduação não obteve contato teórico prático com as modalidades de raquete, não terá aptidão para ensiná-las. Brasil (2001) aponta o preparo inadequado dos professores cuja formação, manteve predominantemente um formato tradicional. O que resulta na comodidade de manter apenas aulas com os esportes coletivos. Porém, cabe aos professores despertar nos alunos o interesse, os sentidos a curiosidade constante na busca pela prática de atividade física continuada.

A oportunidade de uma abordagem de forma criativa gera autonomia de conhecimento processual (B). Ao serem questionados sobre o saber jogar:

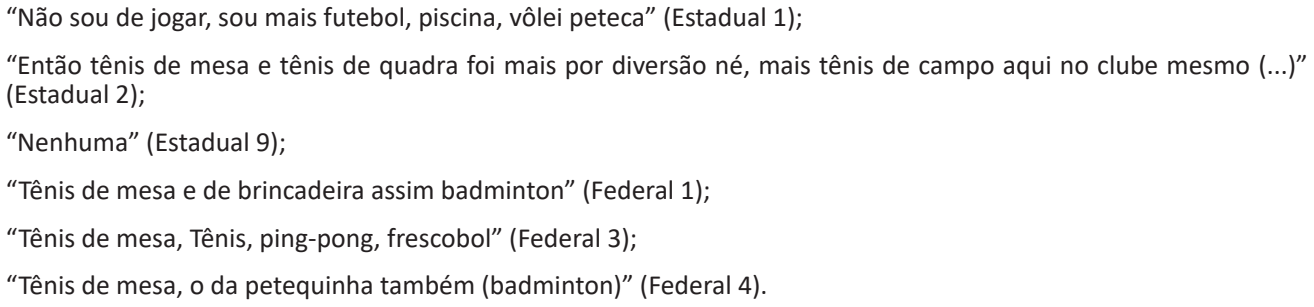

Os entrevistados do estadual apresentaram pouca prática ou uma prática centrada apenas no "ping-pong" (tênis de mesa) se deve ao fato de conhecerem pouco as outras modalidades de raquete, seja por falta de oportunidades de prática, seja, por interesse, já os entrevistados da federal apresentam uma prática um pouco mais diversificada. Gonçalves (2012) fala sobre o badminton como um esporte de fácil aprendizagem e afirma que trabalha o desenvolvimento do raciocínio, rendimento esportivo, habilidades psicomotoras e a estratégia. Entretanto não só o badminton, as demais modalidades de raquete apresentam semelhantes aspectos quando praticadas por lazer. Esta associação é derivada do agrupamento de modalidades de habilidades de rebatida que podem ser utilizadas no processo de ensino-aprendizadotreinamento para facilitar a aquisição e possibilitar o desenvolvimento da capacidade de jogo (GRECO; SILVA; BENDA, 2009).

Rassicci (1986) afirma que é difícil padronizar o planejamento do jogo, é preciso possibilitar que o praticante/ criança possa experimentar. Ou seja, métodos de ensino que despertem a criatividade e compreensão do jogo e mantenham uma prática prazerosa seriam os mais ideais. Fuentes e Gusi (1996) trazem que escolas de tênis ainda utilizam 
de métodos engessados de ensino o que acaba aprisionando o praticante na monotonia. Essa monotonia pode acarretar ao desinteresse pela prática acarretando na desistência da prática continuada.

É necessário modificar com essa metodologia de ensino, que se baseia em uma proposta metodológica unicamente mecanicista, caracterizada pela monotonia de exercícios repetitivos (BALBINOTTI, 2009). Defende ainda, que a iniciação ao Tênis deve ser uma experiência divertida, buscando o prazer do aluno, motivando-o à prática do jogo, buscando ensiná-lo desde a infância, pois o Tênis é considerado um esporte com muitos movimentos complexos. Para Ryan e Deci (2001), o sentimento de bem-estar advém do prazer que o indivíduo sente ao executar as atividades que atendem às suas necessidades. Wankel (1993) afirma que o prazer oferecido pela atividade física é responsável pela manutenção da prática, oportunizando a obtenção de benefícios psicológicos e físicos.

O que corrobora a justificativa dada à pesquisa, que visa encontrar os motivos e características que possibilitam o profissional de educação física trabalhar com os esportes de raquete no nível de rendimento esportivo por lazer ou saúde. Dando à população uma prática planejada, organizada, sistematizada e prazerosa. Uma prática bem estruturada e planejada possibilita maior nível de motivação e interesse do praticante e dos organizadores das modalidades. A motivação poderia ser viés para sustentar os jovens na prática e consequentemente aumentar os níveis de divulgação e a busca da própria prática.

\footnotetext{
"Eu sinceramente teria interesse não. Eu dependendo teria sim. Mais o ping-pong mesmo" (Estadual 1);

"Muito, ela (professora) pega no nosso pé todo dia para jogar" (Estadual 4);

"Tênis normal teria, mas falta projeto, você não vê tênis em qualquer lugar, só o que tem é pago e a maioria não tem condições de pagar" (Estadual 8);

"Incentiva. Incentiva demais" (Estadual 7);
}

"Acho que sim, para conhecer acho que sim, para conhecer sim. E porque a gente tem tipo assim os temas relacionados a tal coisa, o bimestre é relacionado a tal coisa, dança a gente só faz danças, depende do que a gente vai fazer durante o curso, mais se tivesse no planejamento a gente fazia" (Federal 2);

“Não, não, sim, não, Sim. Incentiva, não, vamos ser sinceros ele incentiva a gente que não gosta" (Federal 3);

"Não, não, talvez, talvez, sim. Eu não sou daqui, mas se eu tivesse oportunidade eu teria. Não muito, fica mais como possibilidade, quando a gente vai lá no CEL, fica livre lá, mas não tem nenhuma atividade que vá "forçar" a gente, um incentivo assim" (Federal 5).

Ficou visível que alguns dos entrevistados nos grupos não apresentam interesse para a prática, mesmo com incentivo. Seja do professor ou de outra pessoa, amigo ou familiar. Entretanto a grande maioria, cerca de $75 \%$ dos alunos entrevistados da escola estadual mostrou interesse em conhecer ou praticar alguma das modalidades dos esportes de raquete. Já da escola federal, os interessados foram poucos. Quanto ao incentivo/motivação por parte do professor foi apresentado por eles à questão de terem que seguir um planejamento já estabelecido que envolva essas modalidades. E ainda assim na escola federal tem disponível um local para prática dentro da própria escola que pode ser para a continuidade do aprendizado das aulas de educação física.

Segundo Berleze, Vieira e Krebs (2002), conhecer os motivos que levam um aluno a praticar uma atividade motora na escola pode colaborar com o processo de ensino-aprendizagem já que motivação e aprendizagem são processos mútuos ao ser humano. Betti (1992) afirma que a educação física permite vivenciar diferentes práticas corporais que vem de diferentes manifestações culturais, e que o aluno enxergue como tal combinação de influências está contida no dia a dia.

Chiminazzo (2008) aponta que não cabe ao professor reclamar da falta de espaço, falta de material, etc. O professor é responsável por estimular seus alunos, levando-os à construção do próprio conhecimento. O conhecimento diversificado e adequado as características culturais da região auxiliam na busca de espaços e práticas que possibilitem ao professor alcances de desenvolvimento motores com seus alunos que superam a falta de estrutura disponibilizada pela gestão.

Nas relações entre as categorias de conhecimento processual e conhecimento declarativo percebe-se que os entrevistados têm focos diferentes. Um visa o nível de desempenho e os outros a disponibilidade de prática esportiva para a sociedade independente do alcance competitivo.

\footnotetext{
"Tudo é possível né, basta ter boa vontade e pessoas a fim de levar a coisa à frente né, tem se, principalmente quando fala no esporte de raquete a gente reduz muito a questão do tênis de quadra, que é uma modalidade que tem uma raquete, leva a questão do custo, mas você pode ter alternativas para difundir esta possibilidade de jogar o tênis. Espaço nós temos, agora falta às iniciativas" (Entrevistado 1);

"Projeto mais forte e em Itabirito na academia de tênis, em Ouro Preto não vejo muito, assim divulgação o pessoal não dá muita ênfase no tênis não" (Entrevistado 2);

"Sim, principalmente o tênis, que está super em alta, agora o badminton acho muito interessante para a área escolar, é fácil de jogar, é mais acessível" (Entrevistado 3).
}

A última categoria busca o conhecimento sobre a divulgação das modalidades e foi feita a seguinte pergunta aos grupos: Vocês sabem se tem algum espaço em Ouro Preto que ofereça alguma modalidade? Para esta questão foram dadas as seguintes respostas: 


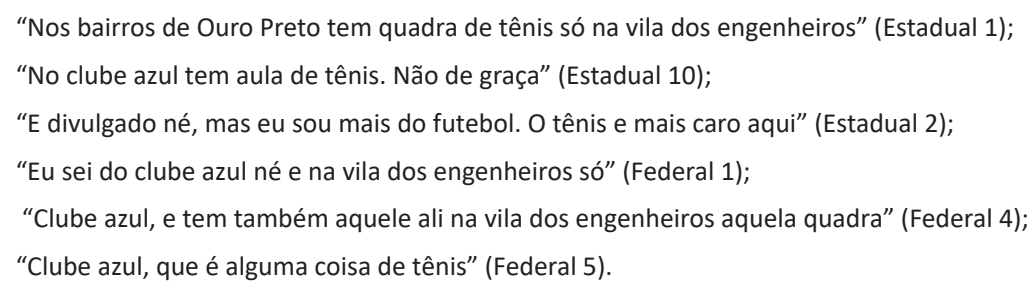

As respostas colaboram e relacionam com as respostas dos entrevistados individuais, quando questionados sobre a divulgação das modalidades de raquete na região, ao qual apresentaram as respectivas respostas:

\footnotetext{
“Pouquíssimo, a única coisa que a gente ouve falar e justamente que eles não divulgam. Nem mesmo a própria secretaria do esporte a gente não observa iniciativas dessa natureza. Se não através dos clubes como o clube azul não se tem notícias, tirando óbvio a questão escolar que é outro fato" (Entrevistado 1);

"Eu acho que tem que divulgar os esportes e as aulas e o seu trabalho" (Entrevistado 2);

“Não, eu sei por que eu vou e um comenta com o outro por aí, mas não tem uma boa divulgação” (Entrevistado 3).
}

Um fato em comum os entrevistados é que todos conhecem sobre os locais de prática, material e profissionais qualificados para o ensino de alguma das modalidades de raquete. Porém a divulgação dessas iniciativas é bastante falha, e isso faz com que não atinjam público em quantidade satisfatória e mantenha as práticas dessas modalidades centradas apenas em poucos indivíduos, muitas vezes mais favorecidos financeiramente.

Sobre essa centralização em poucos indivíduos Oliveira (2017) afirma que o badminton é uma prática bastante sociável, que traz todos os aspectos de um esporte de lazer, e podem ser praticados por todas as faixas etárias, sexos, e de forma simultânea e raramente gera lesões ou apresenta riscos aos praticantes. Essa característica é reforçada nos dias atuais quando muito se discute as questões de gêneros nos esportes. O mesmo vale para as demais modalidades abordadas nesta pesquisa.

Segundo Betti (1998), a mídia se encontra em toda parte e o esporte está presente em toda mídia, o que significa que é possível inserir o esporte em toda e qualquer mídia de divulgação. Isso possibilita uma ampla variedade de formas de se atingir o público/população emergente para a busca de uma prática esportiva que apresente novas práticas, novas vivências e modalidades além do ciclo do "quarteto fantástico". Estudos que buscam caracterizar uma situação muitas vezes se limitam ao conhecimento do pesquisador, restringindo o alcance do olhar. Os horizontes em uma cidade pequena podem facilitar o acesso a novos conhecimentos da região por indicações da própria população, mas ao mesmo ponto circunscrevem os achados.

\section{CONSIDERAÇÕES FINAIS}

Com esta pesquisa foi possível concluir que a prática dos esportes de raquete em Ouro Preto, é uma prática viável, visto que a cidade apresenta estrutura física que possibilita a prática de algumas das modalidades. Apresentam profissionais interessados e com capacidade para exercer a função do ensino, e principalmente apresenta público que, apesar de não ter muita vivência com as modalidades, apresenta interesse para a prática. Mas vale ressaltar, para que ocorra uma continuidade na prática dos esportes de raquete ou até mesmo para o início da prática é importante que a divulgação seja planejada estruturada e organizada de forma que possa atingir todos interessados e despertar o interesse daqueles que nunca tiveram a oportunidade de vivenciar essas modalidades esportivas.

O grande alcance desse estudo está na sua continuidade para os profissionais de educação física que diante do exposto podem explorar o mercado de trabalho na cidade com práticas voltadas aos conhecimentos básicos da população, com metodologias que atendam à prática continuada assegurando novas pesquisas, como por exemplo, metodologia de ensino os esportes de raquete nas aulas de educação física.

\section{REFERÊNCIAS}

BALBINOTTI, C. O ensino do tênis: novas perspectivas de aprendizagem. Porto Alegre: Artmed; 2009.

BERLEZE, A.; VIEIRA, L, F.; KREBS, R, J. Motivos que levam crianças para a prática de atividades motoras na escola. Revista da Educação Física, Maringá, v. 13, n. 1, p. 99-107, 2002.

BETTI, M. A janela de vidro: esporte, televisão e educação física. Campinas: Papirus, 1998.

BETTI, M. Educação física e mídia: novos olhares outras práticas. Florianópolis: Hucitec, 2003.

BETTI, M. Ensino de primeiro e segundo graus: educação física para quê? Revista Brasileira de Ciências do Esporte, Campinas, v. 13, n. 2, p. 282-7, 1992. 
BRASIL. Ministério da Educação. Conselho Federal de Educação. Conselho Nacional de Educação. Parecer CNE/CP n. 009/2001, de 8 de maio de 2001: Institui as Diretrizes Curriculares Nacionais para a formação de professores da educação básica, em nível superior, curso de licenciatura, de graduação plena. Brasília, 2001. Disponível em: <http://portal.mec.gov.br/cne/arquivos/pdf/009.pdf> Acessado em: 1 de amrço de 2018.

CARVALHO, A. M. de. O dirigente esportivo voluntário. Lisboa: Livros Horizonte, 1997.

CARVALHO, B. L. P. Associativismo, lazer e esporte nos clubes sociais de Campinas. 2009. 182f. Dissertação (Mestrado em Educação Física) - Universidade Estadual de Campinas, Campinas, 2009.

CHIMINAZZO, J. Esporte de raquete na escola: uma possibilidade de trabalho. Movimento e Percepção, São Paulo, v. 9, n. 12, p. 1-4, 2008.

CORTELA, C.C; FUENTES, J. P; ABURACHID, L. C. M; KIST, C; CORTELA, D. N. R. Iniciação esportiva ao tênis de campo: um retrato do programa play andstay à luz da pedagogia do esporte. Conexões, Campinas, v. 10, n. 2, p. 214-34, 2012.

DAÓLIO, J. Da cultura do corpo. 11. ed. Campinas: Papirus, 2007.

FUENTES, J P.; GUSI, N. Iniciación jugada ala técnica y a la táctica en el tenis: espacios reducidos y poco material. Cáceres: Copegraf, 1996.

GALLAHUE, D; OZMUM, J. Compreendendo o desenvolvimento motor. São Paulo: Phorte, 1992.

GONÇALVES, R. SILVA, C, E, M. ARAÚJO, L, C. BELLANÇON, A. A importância da tomada de consciência no jogo badminton. Fiep Bulletin, v. 82, Special Edition, Article I, 2012.

GRECO, P. J.; SILVA, S. A.; SANTOS, L. R. Organização e Desenvolvimento Pedagógico do Esporte no Programa Segundo Tempo. In: OLIVEIRA, A. A. B.; PERIM, G. L. (Orgs.). Fundamentos pedagógicos do programa segundo tempo: da reflexão á prática. 21. ed. Maringá: 2009. p. 163-206.

MILANI, A. G.; DARIDO, S. C. Os conteúdos atitudinais no currículo de educação física do estado de São Paulo. Pensar a Prática, Goiânia, v. 19, n. 2, p. 448-61, 2016.

MORENO, J. Fundamentos del deporte. Análisis de lãs estructuras Del juego deportivo. 3. ed. Barcelona: INDE, 1994.

$\mathrm{NITSCH}$, J. R. The Action - theoretical perspective 1. International Review for the Sociology of Sport, Thousand Oaks, v. 20, n. 4, p. 263-282, 1985. 1985.

OLIVEIRA, A. R. P.; GONÇALVES, A. G; SEABRA JUNIOR, M. O. Badminton e esporte adaptado para pessoas com deficiência: revisão sistemática da literatura. Sobama, Marília, v. 18, n. 1, p. 93-108, 2017.

RAMOS, V. O conhecimento pedagógico do conteúdo: estrutura e implicações à formação em educação física. Revista Brasileira de Educação Física e Esporte, São Paulo, v. 22, n. 2, p. 161-7, 2008

RASICCI, A. Enseñanza del tenis primario. Madrid: Real Federación Española de Tenis, 1986. p. 17-22.

RYAN, R. M.; DECl, E. L. On Happiness and Human Potentials: a Review of Resarch on Hedonic and Eudaimonic Well-Being. Annual Review Psychology, Palo Alto, n. 52, p. 141-166, 2001.

THOMAS,J. R.; NELSON, J.K.; SILVERMAN, S. J. Métodos de pesquisa em atividade física. 5. ed. Porto Alegre: Artmed, 2007

TINÔCO, R. D. G. Apontando possibilidades para o ensino do Badminton na Educação Física escolar. Cadernos de Formação RBCE, Porto Alegre, v. 5, n. 1, p. 1-9, 2014

WANKEL, L. M. The Importance of Enjoyment to Adherence and Psychological Benefits from physical Activity. International Journal of Sport Psychology, Rome, v. 24, p. 151-169, 1993.

Autor correspondente: Siomara Aparecida da Silva

E-mail: siomarasilva.lamees@gmail.com

Recebido: 15 de abril de 2018.

Aceito: 04 de outubro de 2019. 